\title{
Impact of Risk Aversion on Optimal Market Integration
}

\author{
Hiroaki Ohno \\ Meiji Gakuin University, Tokyo, Japan
}

\begin{abstract}
This paper examines the equilibrium growth rate of capital stock and social welfare under an infinite-horizon economy with productivity shocks. The analysis is conducted in an international context where the volatility of production is assumed to be endogenously determined by the degree of market integration. The evidence suggests that when risk aversion is high, endogenous productivity risks can induce precautionary savings and the over-accumulation of capital stock, whereas spillovers from integrated markets are conducive to the under-accumulation of capital stock. Only in this case does a unique equilibrium exist in which partial market integration contributes to growth and social welfare. When risk aversion is low, there exist multiple equilibria depending on the degree of market integration, and full market integration is desirable for social welfare. The model gives an explanation of the withdrawal of the United Kingdom from the European Union as an example of rational market participation decisions.
\end{abstract}

JEL classification: E21, F15.

Keywords: Endogenous Productivity Shocks, Optimal Market Integration, Economic Growth, Social Welfare, Risk Aversion.

\footnotetext{
* Corresponding Author: Hiroaki Ohno; Department of Economics, Meiji Gakuin University, 1-2-37 Shirokanedai, Minato-ku, 1080071 Tokyo, Japan, Tel: +81 354215342, Fax: +81 354215207, E-mail:ohno@eco.meijigakuin.ac.jp

Acknowledgements: I am very grateful to Yuichi Fukuta, Yuzo Honda, Shinsuke Ikeda, Nabil Maghrebi, Kazuhiko Nishina, Takayuki Ogawa, Wataru Ohta, Shiba Suzuki, Hirofumi Uchida for their invaluable advice. I am especially indebted to the anonymous referees of this paper for their numerous constructive comments. I take responsibility for the errors remaining in the paper, if any. This research is financially supported by the Grants-in-Aid for Scientific Research for Young Scientists No. 25780206, JSPS, Japan.
} 


\section{Introduction}

Financial regulation in many developed countries does not target full market integration even though social welfare tends to improve with increased integration. Instead, countries appear to target partial market integration, as evidenced in the cases of European Union (EU), the North American Free Trade Agreement (NAFTA), Mercado Común del Sur (Mercosur), and the Association of Southeast Asian Nations (ASEAN), inter alia. According to a broad consensus among academics and policy makers, this pursuit of integration is partly explained by the fact that financial integration reduces macroeconomic fluctuations and transaction costs and improves allocative efficiency. However, the current theoretical evidence about the effectiveness of full integration is not conclusive. This paper explores the rationale behind market segmentation and shows that perfect integration may not be conducive to a participation equilibrium and that perfect international risk-sharing conditions may not necessarily improve social welfare.

Figure 1 shows the hypothetical effect of market integration on the volatility of the aggregated Gross Domestic Product (GDP) growth rate listed on World Development Indicator (WDI) of the World Databank. ${ }^{1}$ The standard deviation of the growth rate does decrease as the degree of integration increases. This implies that perfect market integration would allow each country to diversify its idiosyncratic risks.

\footnotetext{
'The horizontal axis represents the number of aggregated countries, and the vertical axis is the Standard deviation of the growth rate of aggregated GDP listed by World Development Indicator of World Bank. The maximum number of countries is 111, and the time period is from 1970 to 2011. The growth rate of aggregated GDP is derived from $\sum_{i=1}^{N} G D P_{i t+1} / \sum_{i=1}^{N} G D P_{i t}$, where $\mathrm{N}=1, \ldots, 111$ in descending order of the magnitude of GDP.
} 


\section{Figure 1. Volatility of aggregated GDP growth rate}

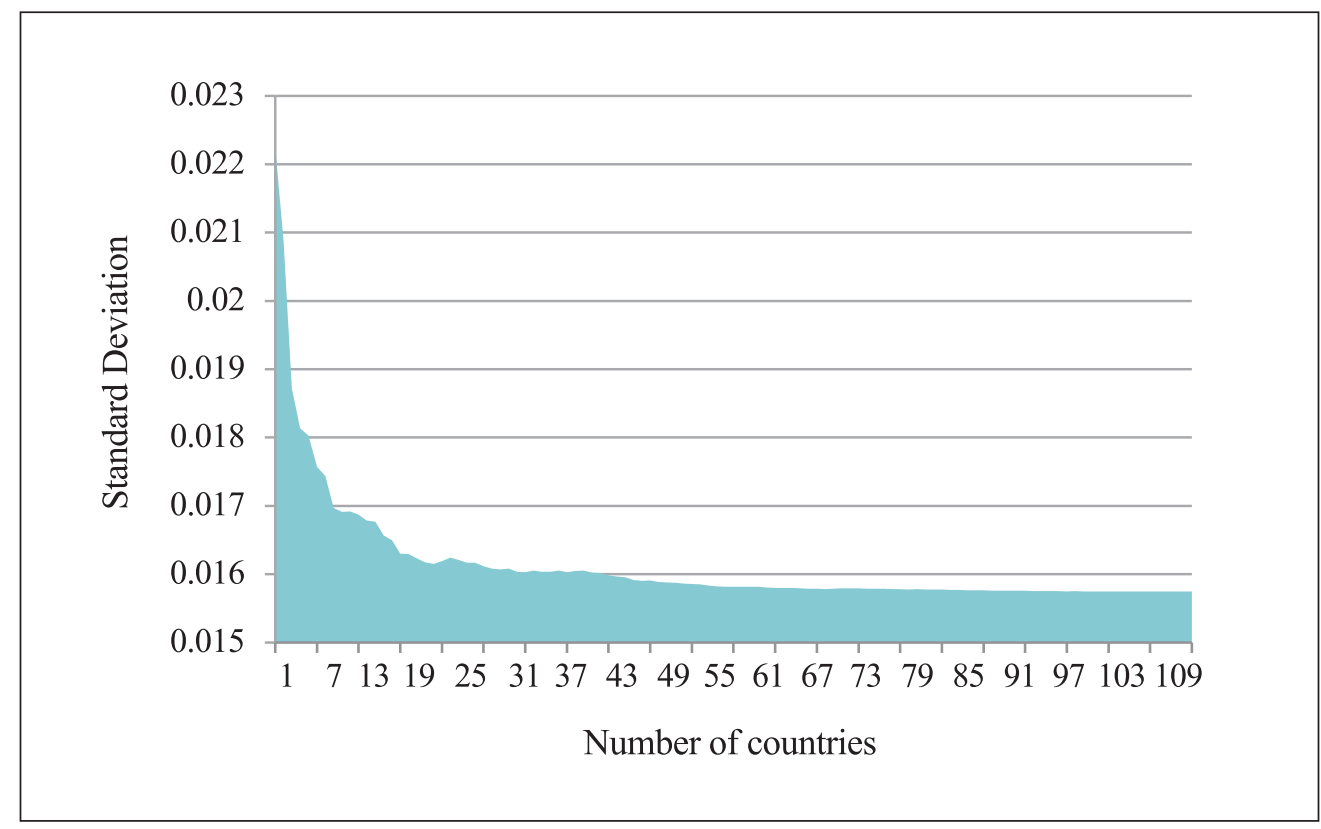

(Note) This figure illustrates the risk-sharing effect of the productive sector of 111 countries listed on the World Development Indicator (WDI) of the World Data Bank.

(Sources) 1970 2010, WDI of World Data Bank.

The equilibrium growth rate of capital stock and social welfare are examined by incorporating endogenous volatility of production into an infinite-horizon economy. This endogenous volatility is generated through risk-sharing externalities. Productivity risks are assumed to be diversifiable when all countries decide to participate in the same risk-sharing group because it is not possible to fully diversify such risks if countries elect to participate into different groups. This model of market integration implies that endogenous volatility may induce precautionary savings and the over-accumulation of capital stock. In addition, when there are spillovers from the segmented market into the production technology, spillover effect on production can be conducive to the underaccumulation of capital stock.

This theoretical evidence is consistent with the previous literature. Devereux and Smith (1994) demonstrate that international risk sharing has the potential to diversify away income risk and therefore reduce savings. ${ }^{2}$ They also provide evidence that,

\footnotetext{
${ }^{2}$ The simple example of risk-sharing externality is described in Appendix 1.
} 
relative to the case of financial autarky, economic growth is likely to decrease under financial integration. Other studies, however, support of the notion that financial market integration enhances social welfare. The empirical evidence forwarded by, for instance, Prasad et al. (2003), Baele et al. (2004), and Kim et al. (2006), as well as the theoretical models proposed by Dumas and Uppal (2001), Molana and Montagna (2006), and Obstfeld (1994) are in line with this notion.

The model of international risk sharing with endogenous production shocks used in this paper differs from the approach used in other studies that assume idiosyncratic shocks to be exogenous. In contrast to the models with exogenous idiosyncratic risks proposed by Aiyagari (1994), Angeletos and Calvet (2006), Devereux and Smith (1994), Huggett (1993), Mankiw (1986), and Weil (1992), it is possible to consider the optimal market integration, as demonstrated by Ohno's $(2009,2010)$ analyses of risk-sharing externalities. In this endogenous volatility model, representative agents who forecast the size of the market and the scope of risks faced ascertain the market participation decision problem depending on their preferences. This enables us to investigate the optimal market integration. Furthermore, the present paper focuses on productivity shocks where risky interest rates do not necessarily promote households savings, whereas Ohno (2009, 2010) considers the effects of endowment shocks and riskless interest rates that induce precautionary savings as long as there is positive risk aversion. In an economy with risky interest rate, however, the promotion of savings depends on the degree of risk aversion and parameters on production technology. This paper clarifies the determinants of equilibria based on these exogenous parameters. The contributions of the infinite-horizon economy model used in this paper are threefold. First, the model suggests that the effect of market integration on economic growth is a function of the degree of risk aversion, and that the optimal degree of market integration is determined by rational market participation decisions. Second, when risk aversion is low, there are multiple market integration equilibria, and in this case, equilibrium with perfect market integration is desirable. Finally, an increase in market integration depresses growth rates if the degree of risk aversion is high, and there is no equilibrium with full market integration. However, market segmentation equilibrium contributes to economic growth and social welfare.

The remainder of the paper is organized as follows. Section II introduces the economic modeling and examines the utility maximization problem. Section III considers the participation decision for each representative agent and characterizes the equilibrium conditions in terms of the degree of market integration. Section IV provides 
a numerical example that explains the theoretical implications. Section V discusses policy implications and comparisons.

\section{Model}

Consider a world economy with a continuum of countries normalized to unity and a single consumption good. ${ }^{3}$ In each country, there is a representative agent with an infinite lifetime. Time is discrete, starts in period 0 , and continues indefinitely, so that $t=0,1,2, \ldots$. Representative agents have to decide whether to join one of two productive risk-sharing mechanisms. These groups are hereafter denoted as $i$, where $i=A$ or $B$. The difference between the two groups depends on the properties of the productivity shocks.

Each representative agent holds capital $k_{i t}$ at $t$ and inelastically supplies $l_{i t}$ hours, which is normalized to one. The representative agents in group $i$ produce the same consumption good according to the production function $\tilde{y}_{i t}=\tilde{\theta}_{i t} k_{i t}^{\alpha}\left(H_{i t} l_{i t}\right)^{1-\alpha}$, where $\tilde{\theta}$ stands for stochastic, Hicks-neutral technology and $\alpha \in(0,1)$ reflects the capital share. $H_{i t}$ represents the spillover effect, which acts as the Harrod-neutral technology growth parameter. Following Romer $(1986,1987)$, it is assumed that in equilibrium, $H_{i t}=\bar{k}_{i t}$, which constitutes the average capital stock. To allow for a closed-form solution for this economy, it is also assumed that capital depreciates fully within a period. The shocks to Hicks-neutral technology are given by $\left\{\tilde{\theta}_{i t}\right\}_{t=0}^{\infty}$ for $i=A, B$.

Each agent must decide whether to belong to alternative risk-sharing mechanisms denoted by groups $i, i=A$ and $B$ : the distinction between group $\mathrm{A}$ and group $\mathrm{B}$ is dependent on the property of productivity shocks. To provide an intuitional explanation, we illustrate the economic rationale for the shock specification in Appendix 1. Suppose that an aggregate fraction $\mu(\in[0,1])$ of countries are in group $\mathrm{A}$. The productivity shocks for both groups are assumed to be dependent on the proportion of membership in group A, $\tilde{\theta}_{i t}(\mu)$, for $i=A, B$. Assume that $\tilde{\theta}_{i t}(\mu)$ is independently and identically distributed over time and that $\tilde{\theta}_{i t}(\mu)$ is strictly positive to avoid negative or zero production output. Furthermore, let $\tilde{\theta}_{i t}(\mu)$ be subject to $\mathrm{E}_{t-1}\left[\tilde{\theta}_{i t}(\mu)\right]=\mathrm{E}\left[\tilde{\theta}_{i t}(\mu)\right] \equiv \bar{\theta}$ and $\operatorname{Var}_{t-1}\left[\tilde{\theta}_{i t}(\mu)\right]=\operatorname{Var}\left[\tilde{\theta}_{i t}(\mu)\right] \equiv \sigma_{i}(\mu)$, where $\sigma_{A}(\mu)$ and $\sigma_{B}(\mu)$ are assumed to be decreasing and increasing, respectively, in $\mu \in[0,1]$.

\footnotetext{
${ }^{3}$ The number of countries can also be assumed to be discrete without loss of generality. However, this setting allows for the analysis of continuous endogenous shocks and equilibrium conditions.
} 
Group A and group B are both assumed to absorb the unilateral productivity shocks in the model without aggregate risk. In a perfectly integrated economy, idiosyncratic shocks are assumed to be diversifiable risks, such that $\tilde{\theta}_{A}(1)=\bar{\theta}$ and $\sigma_{A}(1)=0$ or $\tilde{\theta}_{B}(0)=\bar{\theta}$ and $\sigma_{B}(0)=0$.

Each representative agent consumes $c_{i t}$ goods in period $t$. The agent's preference can be defined as the sum of the expected discounted utility functions under constant relative risk aversion, $V_{i} \equiv E\left[\sum_{t=0}^{\infty} \beta^{t}\left(c_{i t}^{1-\gamma}-1\right) /(1-\gamma)\right]$, where $\beta$ represents the discount factor and $\gamma$ represents the risk aversion parameter.

In this economy, representative agents face a two-stage optimization problem. First, in period 0 , they must decide whether to participate in group A or group B to benefit from risk-sharing opportunities. In particular, the incentive to participate in group A is conditional on $V_{A}>V_{B}$. Next, they face a utility maximization problem. The participation decision can only be made after solving this problem, which is discussed in the following section.

\section{A. Utility maximization problem}

The representative agent in each country faces the following budget constraint:

$$
c_{i t}+k_{i t+1}=\tilde{\theta}_{i t} k_{i t}^{\alpha}\left(H_{i t} l_{i t}\right)^{1-\alpha}
$$

where $k_{0}$ is given. The value function $V_{i}$ can be examined using dynamic programming. The Bellman equation is given by

$$
V_{i t}\left(k_{i t}\right)=\max \left\{u\left(c_{i t}\right)+\beta E_{t}\left[V_{i t+1}\left(k_{i t+1}\right)\right]\right\}
$$

subject to (1). The first-order condition can be derived as

$$
u^{\prime}\left(c_{i t}\right)=\beta E_{t}\left[F_{k_{i t+1}} V_{i t+1}^{\prime}\left(k_{i t+1}\right)\right]
$$

where $F_{k_{i t+1}}$ represents the marginal product of capital. From the envelope theorem (Benveniste and Sheinkman, 1982), the following equation is satisfied:

$$
u^{\prime}\left(c_{i t}\right)=V_{i t}^{\prime}\left(k_{i t}\right)
$$


Using Equation (3) and Equation (4), it is possible to derive the following Euler equation with Constant Relative Risk Aversion (CRRA) preferences:

$$
c_{i t}^{-\gamma}=\beta E_{t}\left(F_{k_{i t+1}} c_{i t+1}^{-\gamma}\right) \text {. }
$$

\section{B. Equilibrium conditions}

This section determines the equilibrium conditions for the capital, labor, and goods markets in order to examine the time-invariant policy function.

The average capital stock is given by

$$
\bar{k}_{i t}=k_{i t}
$$

and in equilibrium, the spillover effect within group $i$ is satisfied when $H_{i t}=\bar{k}_{i t}$. Each representative agent supplies one unit of labor in every period, so labor market clearing requires that $l_{i t}=1$. Hence, the marginal product of capital is as follows:

$$
F_{k_{i t}}=\alpha \tilde{\theta}_{i t}
$$

In equilibrium, the goods market requires that

$$
c_{i t}+k_{i t+1}=\theta_{i t} k_{i t}, \text { for } i=A, B
$$

Using these market-clearing conditions and the Euler equation, the following decision rule can be derived: ${ }^{4}$

$$
k_{i t+1}=\left[\beta \alpha E_{t}\left(\tilde{\theta}_{i t+1}^{1-\gamma}\right)\right]^{1 / \gamma} \theta_{i t} k_{i t}, \text { for } i=A, B
$$

Because $E_{t}\left(\tilde{\theta}_{i t+1}^{1-\gamma}\right)$ is a time-invariant function, the law of motion of capital stock is as follows:

$$
k_{i t+1}=\left[\beta \alpha E\left(\tilde{\theta}_{i}^{1-\gamma}\right)\right]^{1 / \gamma} \theta_{i t} k_{i t} \equiv \psi_{i} \theta_{i t} k_{i t} \text { for } i=A, B .
$$

${ }^{4}$ The proof for the derivation of this decision rule is included in the Appendix 2. 
where $\psi_{i}=\left[\beta \alpha E\left(\tilde{\theta}_{i}^{1-\gamma}\right)\right]^{1 / \gamma}$.

In addition, the time-invariant policy functions are given by

$$
c_{i t}=\left(1-\psi_{i}\right) \theta_{i t} k_{i t} \text { for } i=A, B
$$

where the Marginal Propensity to Consume (MPC) is denoted by $\psi_{i}$ and the Marginal Propensity to Save (MPS) is $\psi_{i}$.

Stochastic productivity is assumed to be binomially distributed in order to derive closed-form solutions.

\begin{tabular}{|c|c|c|}
\hline Group A & Group B & \\
\hline $\bar{\theta}+\lambda(1-\mu)$ & $\bar{\theta}-\lambda \mu$ & With probability $1 / 2$ \\
\hline $\bar{\theta}-\lambda(1-\mu)$ & $\bar{\theta}+\lambda \mu$ & With probability $1 / 2$ \\
\hline
\end{tabular}

$\lambda$ represents the magnitude of productivity shocks and takes only positive values. This simplification is in line with the previous setting and implies that group A countryspecific shocks decrease if $\mu$ rises and vice versa.

In particular, in a perfectly integrated economy, productivity shocks fully disappear, i.e., $\mu=0$ or $\mu=1$. If the fraction of countries in group $\mathrm{A}(\mu)$ decreases, then $\tilde{\theta}_{A}$ becomes more volatile, and precautionary savings are conducive to a higher equilibrium growth rate. The following proposition can thus be introduced:

Proposition 1: Economic growth

An increase in the degree of market integration is conducive to a higher growth rate if $0<\gamma \leq 1$ and to a lower growth rate if $1<\gamma$.

\section{Proof. See Appendix 3}

In the case of endowment risk, the positive constraint of risk aversion is conducive to precautionary savings. Therefore, more risky endowments therefore promote household savings if $0<\gamma$. On the other hand, this model incorporates productivity shocks, which instead can be classified as interest rate risk. The difference between endowment and productivity shocks is whether or not saving involves risk. If the productivity has shocks, then interest rates become volatile. This implies that savings have the risk of return. In 
the case of productivity shocks, precautionary saving arises when relative prudence is larger than two, which corresponds to $1<\gamma$ in the case of CRRA preferences.

\section{Equilibrium Market Integration}

This section derives the lifetime indirect utility for each group in period 0 and characterizes the participation decision. Using Equation (2), Equation (9) and Equation (10), the following lifetime indirect utility can be derived:

$$
V_{i}^{*}\left(k_{0}\right)=\frac{\left(1-\psi_{i}\right)^{1-\gamma} E\left(\tilde{\theta}_{i}^{1-\gamma}\right) k_{0}^{1-\gamma}}{(1-\gamma)\left[1-\beta \psi_{i}^{1-\gamma}\left(\tilde{\theta}_{i}^{1-\gamma}\right)\right]} \text { for } i=A, B
$$

Agents are assumed to have common beliefs about the degree of market integration $\mu$ because this ratio determines their beliefs about the productivity shocks. Indeed, within this participation game, productivity shocks are generated by the degree of market integration. Thus, it is optimal for representative consumers with common beliefs about the degree of market integration to participate in group A if and only if the following condition is satisfied:

$$
\frac{\left(1-\psi_{A}\right)^{1-\gamma} E\left(\tilde{\theta}_{A}^{1-\gamma}\right)}{(1-\gamma)\left[1-\beta \psi_{A}^{1-\gamma}\left(\tilde{\theta}_{A}^{1-\gamma}\right)\right]}>\frac{\left(1-\psi_{B}\right)^{1-\gamma} E\left(\tilde{\theta}_{B}^{1-\gamma}\right)}{(1-\gamma)\left[1-\beta \psi_{B}^{1-\gamma}\left(\tilde{\theta}_{B}^{1-\gamma}\right)\right]}
$$

If the following relation is satisfied, then representative agents are indifferent about participating in group A or group B:

$$
\frac{\left(1-\psi_{A}\right)^{1-\gamma} E\left(\tilde{\theta}_{A}^{1-\gamma}\right)}{(1-\gamma)\left[1-\beta \psi_{A}^{1-\gamma}\left(\tilde{\theta}_{A}^{1-\gamma}\right)\right]}=\frac{\left(1-\psi_{B}\right)^{1-\gamma} E\left(\tilde{\theta}_{B}^{1-\gamma}\right)}{(1-\gamma)\left[1-\beta \psi_{B}^{1-\gamma}\left(\tilde{\theta}_{B}^{1-\gamma}\right)\right]}
$$

The value functions $V_{i}(\mu)$ can be characterized by the parameters $(\beta, \gamma, \theta, \alpha, \lambda)$ as can beliefs about market integration $\mu$. The equilibrium conditions in this model require

${ }^{5}$ Kimball (1990) and Suzuki (2010) investigate these arguments. 
perfect foresight about the degree of market integration, which occurs at a fixed point $\mu^{*}$ where representative agents hold self-fulfilling expectations. This fixed point $\mu^{*}$ can therefore be regarded as sunspot equilibrium. Then, the following proposition can be obtained:

Proposition 2: Multiple equilibria

If $(\gamma+\alpha-1) \psi_{i}<\gamma \alpha, V_{A}(0)<V_{B}(0)$, and $V_{B}(1)<V_{A}(1)$, there exist two types of equilibrium, the full-integration equilibria $\mu^{*}=0.1$ and the market-segmentation equilibrium $\mu^{*}=0.5$.

\section{Proof. See Appendix 4.}

If the restrictions in Proposition 2 are satisfied, the indirect utility of group A dominates that of group B when $\mu^{*}=1$, whereas the indirect utility of group B dominates when $\mu^{*}=0$. If $(\gamma+\alpha-1) \psi_{i}<\gamma \alpha$, then $V_{A}$ is increasing and $V_{B}$ is decreasing in $\mu$. Under these restrictions, the intermediate value theorem is applicable to this model. Thus, there exist multiple equilibria, which are represented by the fully integrated market equilibria $\mu^{*}=0.1$ and the segmented-market equilibrium $\mu^{*}=0.5$.

Note that indirect utility is monotonically increasing in the degree of market integration. This implies that the segmented-market equilibrium is lower than the fullintegration equilibrium. If the model is extended as a repeated game, then the market segmentation equilibrium may be expected to disappear as the degree of market participation increases.

\section{Proposition 3: Unique equilibrium}

If $\gamma \alpha<(\gamma+\alpha-1) \psi_{i}, V_{B}(0)<V_{A}(0)$, and $V_{A}(1)<V_{B}(1)$, then there is a unique equilibrium at $\mu^{*}=0.5$ in the absence of full market integration equilibria.

\section{Proof. See Appendix 4.}

If the restrictions in Proposition 3 are satisfied, the indirect utility of group A dominates that of group B when $\mu=0$ and vice versa when $\mu=1$. If $\gamma \alpha<(\gamma+\alpha-1) \psi$, then $V_{A}$ is decreasing and $V_{B}$ is increasing in $\mu$.

Under these restrictions, there exists a unique equilibrium represented by the segmented-market equilibrium where $\mu^{*}=0.5$. Fully integrated market conditions do not lead to equilibrium because if, for instance, $\mu^{*}=0$, then $V_{B}$ is dominated by $V_{A}$. 
This implies that all representative agents decide to participate in group A. Thus, an equilibrium under full market integration with $\mu=0$ or $\mu=1$ cannot be achieved.

Note again that the indirect utility is monotonically decreasing in the degree of market integration. This implies that even if full market integration can represent an equilibrium point, the indirect utility is lower than that under market segmentation. Therefore, even if the model is extended to a repeated game, the equilibrium under market segmentation still holds.

\section{Numerical Example}

This section illustrates the conclusions of the theoretical model using a numerical example. With CRRA preferences and a Romer-type technology, the economy is fully parameterized by $(\beta, \gamma, \theta, \alpha, \lambda)$. Let the time period be one year and the discount factor $\beta=0.997$. According to Barro and Sala-i-Martin (2003), the income share of capital $\alpha$ is assumed to be 0.4 . Other parameters are explained ad libitum. 
Figure 2. Market integration and economic growth

(when $\gamma=0.999)$

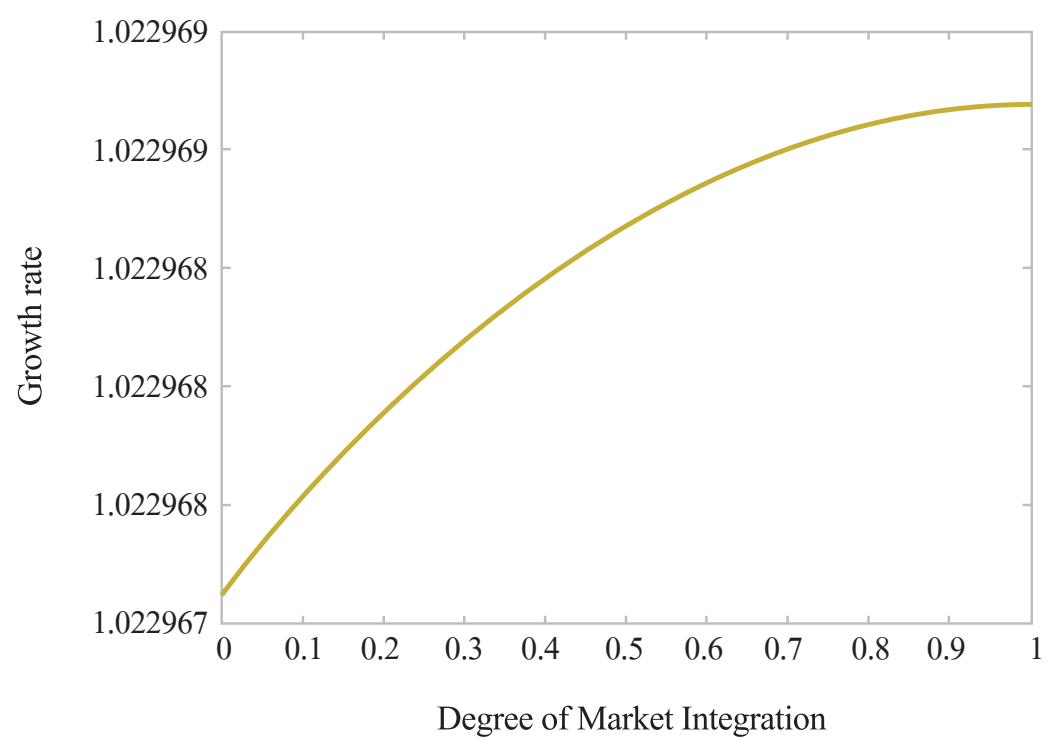

Figure 3. Market integration and economic growth

(when $\gamma=1.0001$ )

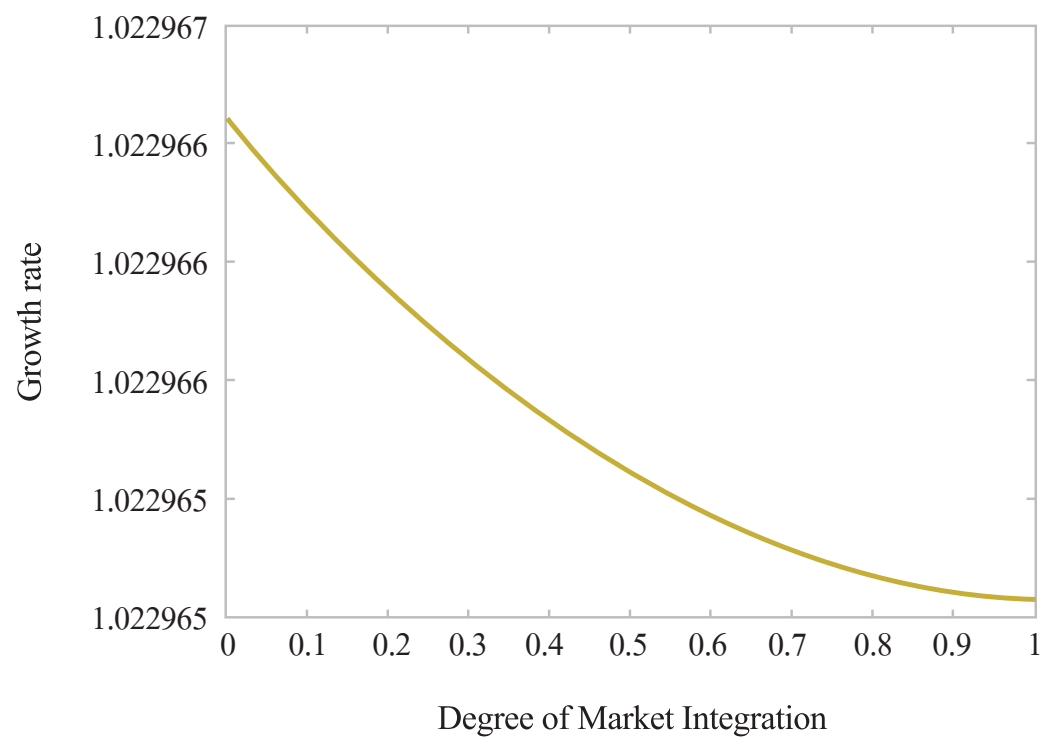


Precautionary savings contribute to increased capital accumulation when the coefficient of risk aversion is larger than one. However, productivity shocks can exert downward pressure on capital accumulation if the degree of risk aversion is smaller than one. The relationship between the degree of market participation and economic growth, as explained in Proposition 1, can be described by Figures 2 and Figure 3. As $\mu$ approaches unity, productivity shocks decrease. In Figure 2, where $\gamma$ is set to be 0.999 , the growth rate of capital stock within group A is shown to be a increasing function of the degree of market integration. By setting $\gamma=1.0001$, however, it is clear from Figure 3 that an increase in the degree of market participation lowers the economic growth rate.

\section{Figure 4. Market integration and indirect utility within group A}

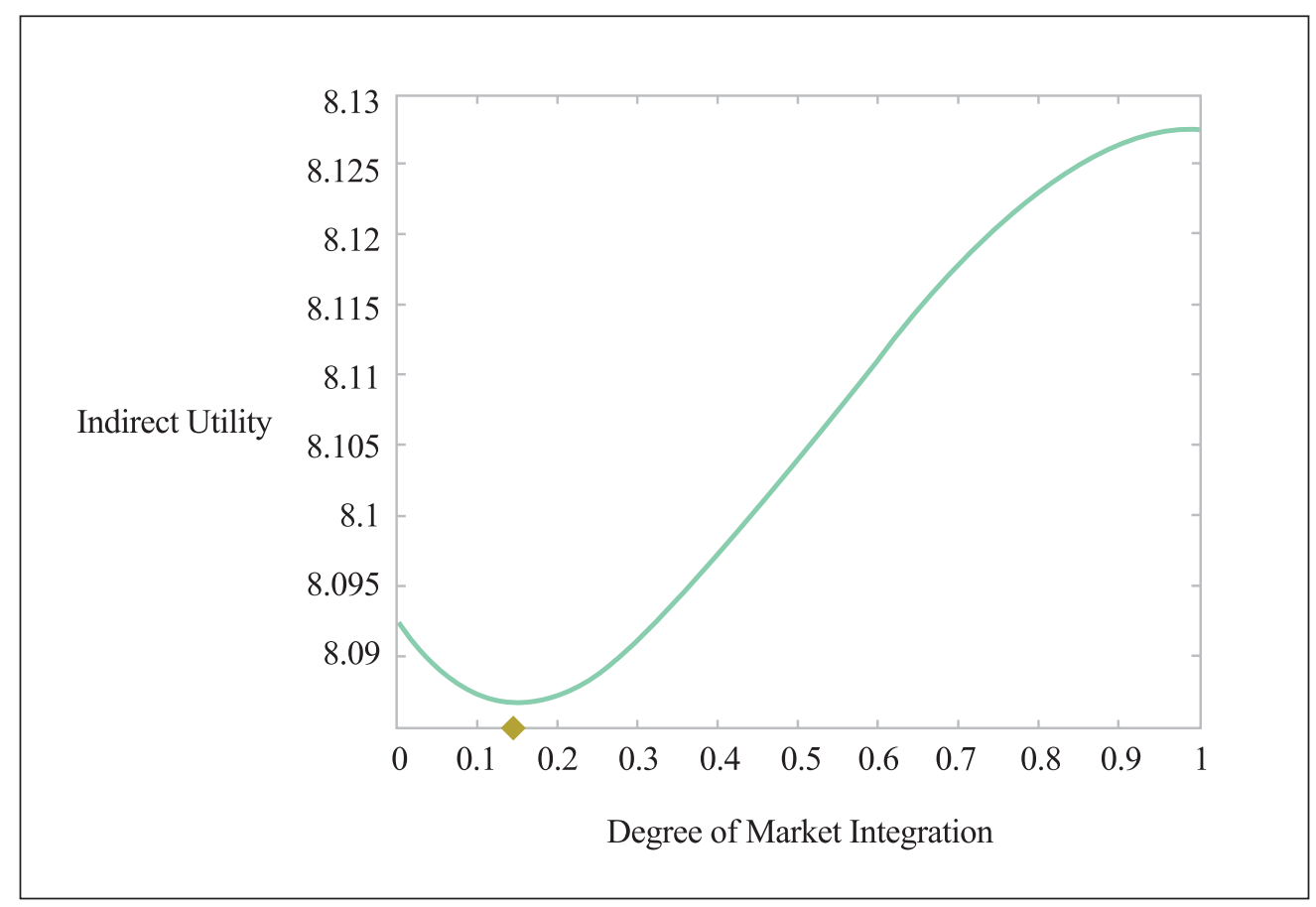

(Notes) (i) Figure 4 represents the case of non-monotonic indirect utility within group A. Depending on magnitude relation between $(\gamma+\alpha-1) \psi_{A}$ and $\gamma \alpha$, the indirect utility of group A increases and decreases.

(ii) The diamond shape represents satisfying $(\gamma+\alpha-1) \psi_{A}=\gamma \alpha$. 
Figure 5. Parameter restrictions under Proposition 2 and 3

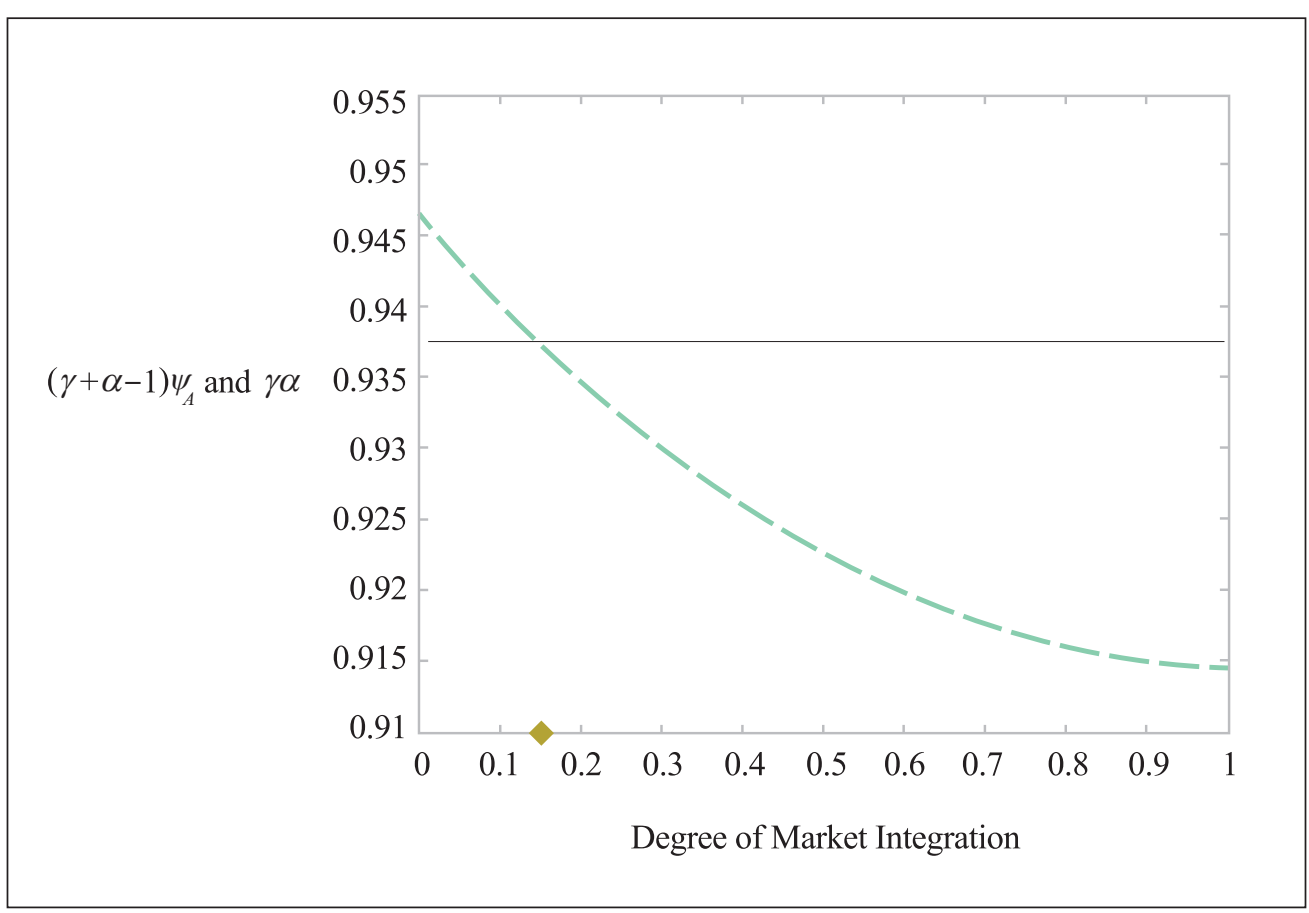

(Notes) (i) Figure 5 demonstrates parameter restrictions on Proposition 2 and 3. The unbroken line in figure 5 represents $\gamma \alpha$ and broken line represents $(\gamma+\alpha-1) \psi_{A}$.

(ii) The diamond shape represents satisfying $(\gamma+\alpha-1) \psi_{A}=\gamma \alpha$.

Figure 4 and Figure 5 describe the lifetime indirect utility of group A under the parameter restrictions in Proposition 2 and Proposition 3. In this calculus, $\gamma \alpha$ is set to 0.937 , and indirect utility is decreasing if the degree of market integration lies within the interval $\mu \in(0,0.15]$, over which the relation $\gamma \alpha<(\gamma+\alpha-1) \psi_{A}$ is satisfied. The indirect utility is increasing, however, for $\mu \in(0.15,1]$, where $\gamma \alpha>(\gamma+\alpha-1) \psi_{A}$. This implies that indirect utility is monotonically increasing in $\mu$ if the restriction $\gamma \alpha>(\gamma+\alpha-1) \psi_{A}$ is satisfied for all $\mu$, but it is monotonically decreasing in $\mu$ when $\gamma \alpha<(\gamma+\alpha-1) \psi_{A}$ for all $\mu$. Thus, the propositions impose monotonicity restrictions on the indirect utility function to ensure the existence of equilibria. 
Figure 6. Multiple equilibria

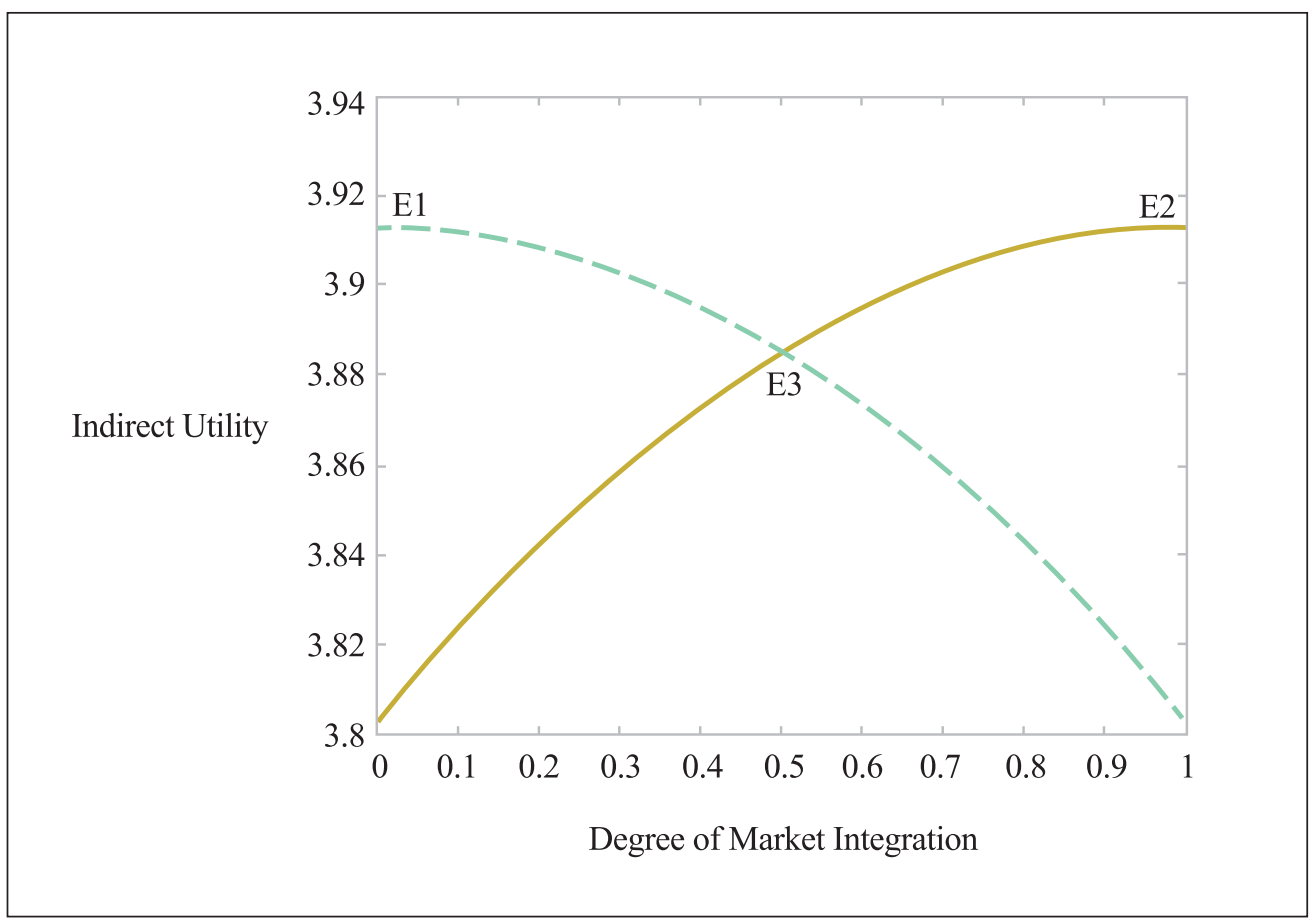

(Note) Figure 6 represents Proposition 2. The unbroken line is indirect utility of group A and the broken line is group B. Also, E1, E2, and E3 represent multiple equilibria, where E1 and E2 are perfect integration equilibria while $\mathrm{E} 3$ is market segmentation equilibrium. 
Figure 7. Social welfare

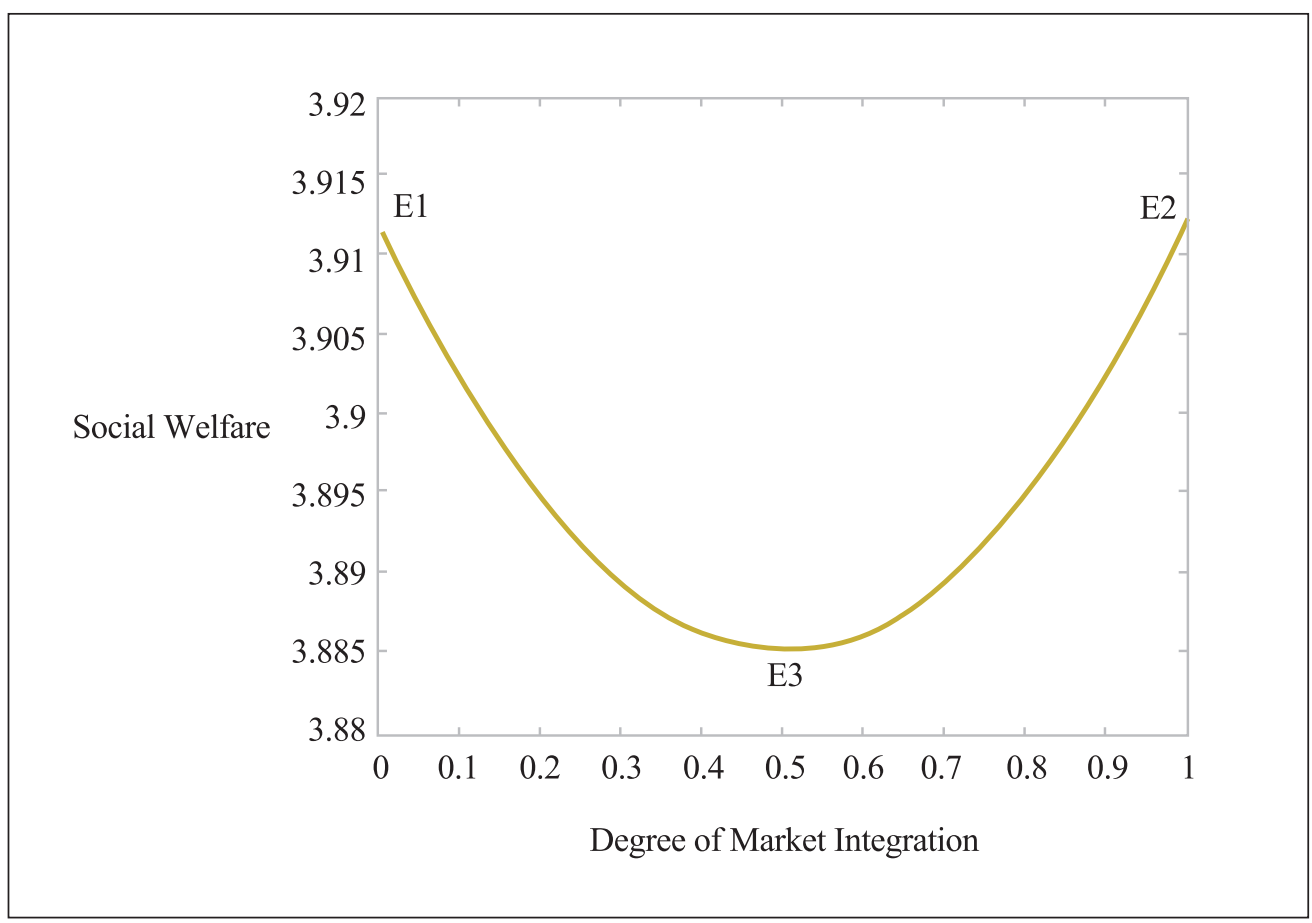

(Note) Figure 7 shows social welfare under lower risk aversion.

The multiple equilibria are examined using productivity $\theta=1.1$ and the scale of productivity shocks $\lambda=0.3$, which implies a thirty percent measure of productivity fluctuations. Figure 6 and Figure 7 are derived given the risk aversion parameter $\gamma=0.5$.

There are two types of equilibrium illustrated by Figure 6: the perfect market integration equilibria E1 and E2 and the market segmentation equilibrium E3. At equilibrium point $\mathrm{E} 1$, all countries have an incentive to participate in group B because the welfare of group A is dominated by that group B. Hence, all countries with common beliefs that $\mu=0$ are induced to join the fully integrated market. Similarly, at equilibrium point E2, there is an incentive for countries to participate in group A because of higher indirect utility. At equilibrium point E3, however, market segmentation is caused by common beliefs that $\mu^{*}=0.5$ and equivalent indirect utilities in groups $\mathrm{A}$ and $\mathrm{B}$.

Figure 7 describes the social welfare function, which is calculated from the definition of $S W \equiv \mu V_{A}+(1-\mu) V_{B}$ Welfare at equilibrium point E1 is equivalent to that at E2, and both dominate welfare at equilibrium point E3. Therefore, the market segmentation 
equilibrium creates lower social welfare, and global market integration may be desirable under lower risk aversion.

Figure 8. Unique equilibrium

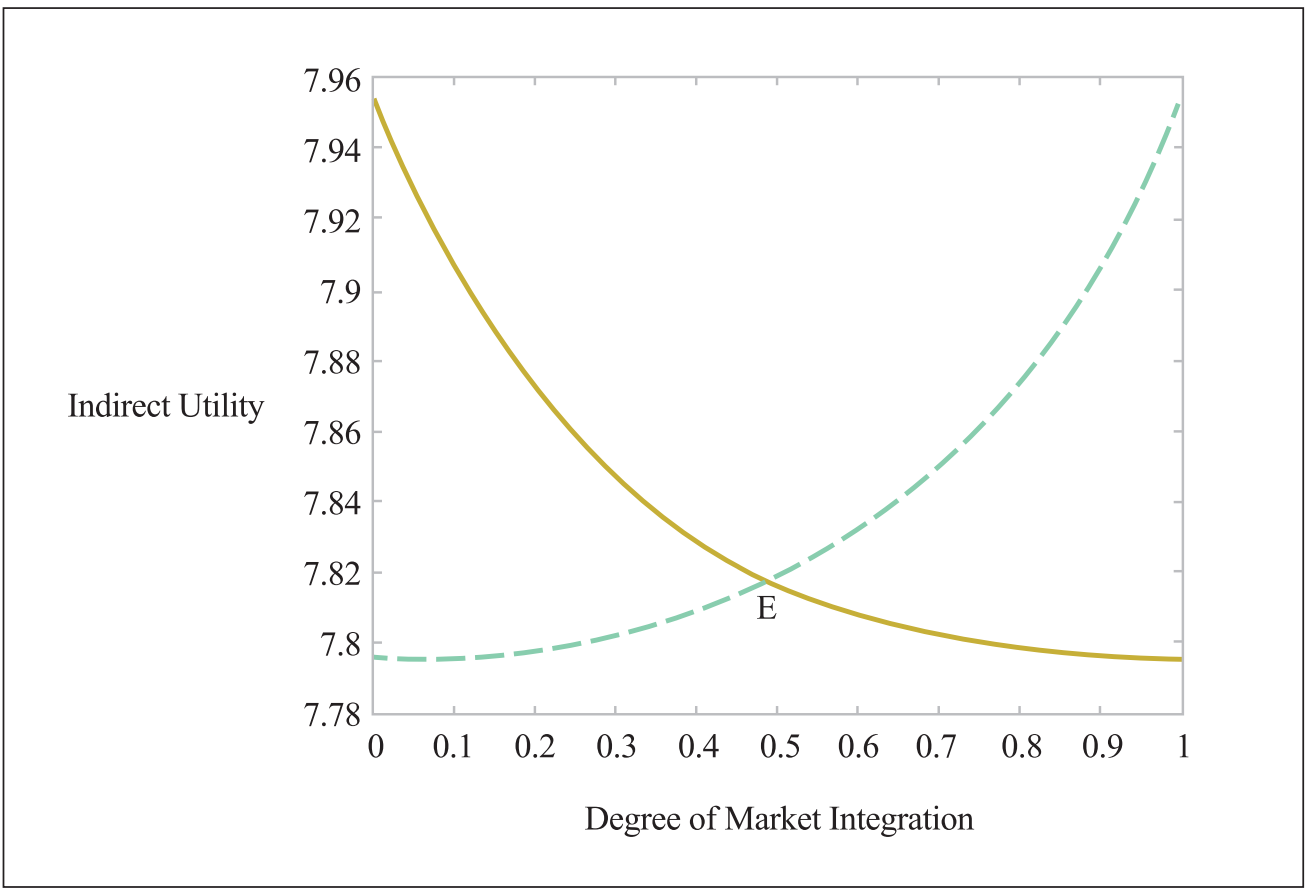

(Note) Figure 8 demonstrates Proposition 3. The unbroken line is indirect utility of group A and the broken line is group B. Also, E represents the unique equilibrium. Also other values of $\mu$ are not supported by optimization and equilibrium. 
Figure 9. Social welfare

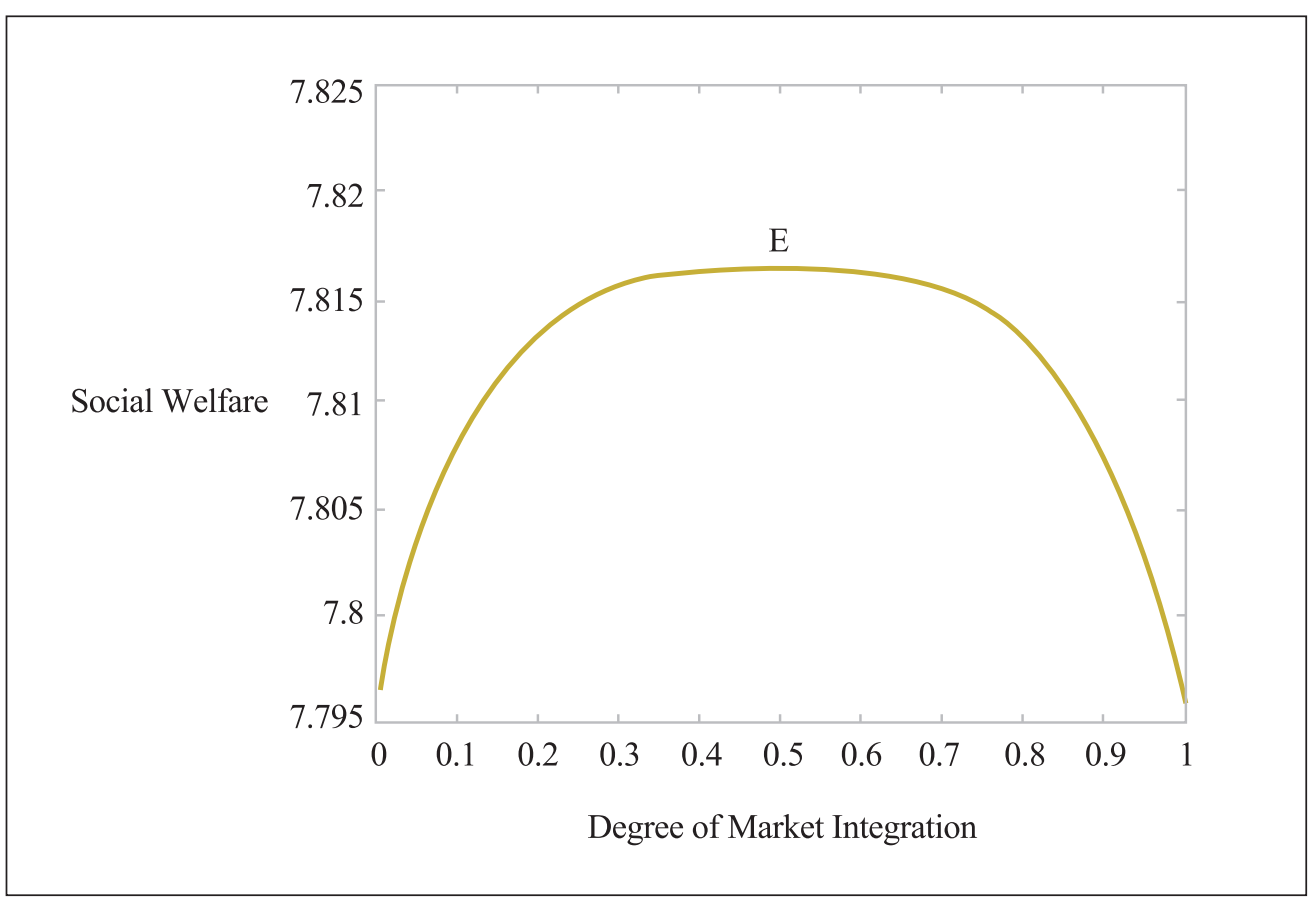

(Note) Figure 9 shows social welfare under high risk aversion.

Figure 8 and Figure 9 demonstrate the implications of Proposition 3 with the degree of risk aversion $\gamma=2$. It is shown that perfect market integration does not constitute an equilibrium point because the indirect utility of group B is dominated by that of group A when $\mu=0$. When this occurs, beliefs about market participation are not realized. For instance, $\mu$ may be forecast to take the value of 0 , with full membership in group $\mathrm{B}$, but an incentive to join group A may arise because of higher indirect utility. This would lead to a deviation from the forecast since $\mu$ ultimately takes the value of unity rather than zero.

There is a case of self-fulfilling expectations at the equilibrium point $\mathrm{E}$, where the degree of market integration is forecast to be $\mu=0.5$, as the indirect utility functions for group A and group B are equivalent. This unique equilibrium E dominates other welfare points for alternative values of $\mu$, as shown in Figure 9. Thus, under higher risk aversion, an equilibrium with perfect market integration cannot be achieved because of its lower social welfare. 


\section{Conclusion}

When low risk aversion is assumed, market segmentation equilibrium is unstable, whereas full integration equilibria are stable. This implies that the economy progresses toward global market integration if participation decision is expanded to a repeated game. However, the segmented market equilibrium is unique and stable under high risk aversion. Additionally, it is impossible to realize full integration even though there are chances of repetition of market participations. Thus, it enables us to characterize equilibrium market integration as a consequence of rational participation decision. This theoretical prediction could suggest the impossibility of global market integration. It is optimal for highly risk-averse agents to avoid participating in global market integration even though it may seem paradoxical. The withdrawal of the United Kingdom (UK) from the EU may be just one example of rational decision making.

This endogenous growth model provides the following empirical and policy suggestions. First, each policy maker among countries should evaluate the relation between the progress of market integration and its effect on growth rate. If an increase in the degree of market integration lowers the growth rate, then, at least, excess market integration has the potential to pervert social welfare. Second, market segmentation can improve welfare only if precautionary savings of households adequately offsets spillover effects on production technology. This implies that policy makers are required to evaluate positive externality effects on technological progress because it induces underaccumulation of capital stocks and requires precautionary motives of households for the realization of preferable economic growth.

The significance of these theoretical results can be assessed in light of the evidence from previous literature concerning the impact of economic and financial globalization on social welfare. For instance, studies by Dumas and Uppal (2001), Molana and Montagna (2006), and Obstfeld (1994) indicate that financial integration increases social welfare. The empirical evidence advanced by Frankel and Rose (1998) suggests that the removal of trade barriers has the potential to induce higher correlations between business cycles because financial market integration allows for demand shocks to be more easily diversified away across national borders. However, the existence of positive externalities of the production function can affect the significance of this relationship. Our theoretical model suggests that country-specific productivity shocks within segmented markets are likely to be more correlated because of risk sharing. This result is, thus, consistent with 
conclusions of Frankel and Rose (1998). This evidence does not support the proposition that financial integration is necessarily conducive to increased social welfare; in fact, in some cases, equilibria exist with higher social welfare under market segmentation.

Market segmentation is conducive to growth only under higher risk aversion, which stimulates precautionary savings and the over-accumulation of capital stock. It is also shown that under these conditions, there is a unique equilibrium where full market integration is not optimal and market segmentation leads to higher social welfare. In contrast, perfect market integration is more desirable under lower risk aversion, which allows for risk-sharing opportunities and higher welfare. Thus, higher degrees of risk aversion impede market integration.

Received 12 June 2016, Revised 13 October 2016, Accepted 26 October 2016

\section{References}

Aiyagari, Rao S. "Uninsured Idiosyncratic Risk and Aggregate Saving," Quarterly Journal of Economics 109 (3) (1994): 659-684.

Angeletos, George M. and Laurent E. Calvet, "Idiosyncratic Production Risk, Growth and the Business Cycle," Journal of Monetary Economics 53 (6) (2006): 1095-1115.

Baele, Lieven, Annalisa Ferrand, Peter Hordahl, Elizaveta Krylova, and Cyril Monnet, "Measuring Financial Integration in the Euro Area," European Central Bank Occasional Paper 14 (2004).

Barro, Robert J. and Xavier I. Sala-i-Martin, Economic Growth. Cambridge, MA: MIT Press, 2003.

Benveniste, Lawrence M. and Jones A. Scheinkman, "Duality Theory for Dynamic Optimization Models of Economics: The Continuous Time Case," Journal of Economic Theory 27 (1) 1982: 1-19.

Devereux, Michael B. and Gregor W. Smith, "International Risk Sharing and Economic Growth," International Economic Review 35 (3) (1994): 535-550. 
Dumas, Bernard, and Raman Uppal, "Global Diversification, Growth and Welfare with Imperfectly Integrated Markets for Goods," Review of Financial Studies 14 (1) (2001): 277-305.

Frankel, Jaffrey A. and Andrew K. Rose, "The Endogeneity of the Optimum Currency Area Criterion, The Economic Journal 108 (1998): 1009-1025.

Huggett, Mark "The Risk Free Rate in Heterogeneous-Agents, Incomplete Insurance Economies," Journal of Economic Dynamics and Control 17 (5) (1993): 953-969.

Kim, Suk-Joong. Fariborz Moshirian, and Eliza Wu, "Evolution of International Stock and Bond Market Integration: Influence of the European Monetary Union,” Journal of Banking \& Finance 30 (5) (2006): 1507-1534.

Kimball, Miles S. "Precautionary Saving in the Small and in the Large," Econometrica 58 (1) (1990): 53-73.

Mankiw, Gregory N. "The Equity Premium and the Concentration of Aggregate Shocks," Journal of Financial Economics 17 (1) (1986): 211-219.

Molana, Hassan and Catia Montagna, "Aggregate Scale Economies, Market Integration, and Optimal Welfare State Policy," Journal of International Economics 69 (2) (2006): $321-340$.

Obstfeld, Maurice "Risk-Taking, Global Diversification, and Growth," American Economic Review 84 (5) (1994): 1310-1329.

Ohno, Hiroaki "Incomplete Market Participation, Endogenous Endowment Risks and Welfare," Journal of Economics and Business 61 (5) (2009): 392-403.

Ohno, Hiroaki "Risk-Sharing Externalities and its Implications for Equity Premium in an Infinite-Horizon Economy," Czech Economic Review 4 (2) (2010): 168-188.

Prasad, Eswar, Kenneth Rogoff, Shang-Jin Wei, and M. Ayhan Kose, "Effects of Financial Globalization on Developing Countries: Some Empirical Evidence," IMF Occasional paper 220 (2003).

Romer, Paul M. "Increasing Returns and Long-Run Growth," Journal of Political Economy 94 (5) (1986): 1002-1037.

Romer, Paul M. "Growth Based on Increasing Returns Due to Specialization," American Economic Review 77 (2) (1987): 56-62. 
Suzuki, Shiba "Risks after Disasters: A Note on the Effects of Precautionary Saving on Equity Premiums" Economics Bulletin 29 (2009): 328-337.

Weil, Philippe "Equilibrium Asset Prices with Undiversifiable Labor Income Risk," Journal of Economic Dynamics and Control 16 (1992): 769-790. 


\section{Appendix 1: Explanation for risk-sharing externalities}

To provide an intuitional explanation, we illustrate the following example. Let us consider four states and four countries. Assume that each country will receive the following endowments in the future.

Table A1. Endowment matrix

\begin{tabular}{|l|c|c|c|c|c|}
\hline & Country 1 & Country 2 & Country 3 & Country 4 & \\
\hline State 1 & 5 & 1 & 1 & 1 & With Probability $1 / 4$ \\
\hline State 2 & 1 & 5 & 1 & 1 & With Probability $1 / 4$ \\
\hline State 3 & 1 & 1 & 5 & 1 & With Probability $1 / 4$ \\
\hline State 4 & 1 & 1 & 1 & 5 & With Probability $1 / 4$ \\
\hline
\end{tabular}

For example, country 1 receives five units of the consumption good when state 1 is realized; however, the other countries obtain one unit only. If all of the countries belong to the same risk-sharing mechanism, then they can smooth their consumption, that is, as follows.

Table A2. Consumption matrix

\begin{tabular}{|l|c|c|c|c|c|}
\hline & Country 1 & Country 2 & Country 3 & Country 4 & \\
\hline State 1 & 2 & 2 & 2 & 2 & With Probability $1 / 4$ \\
\hline State 2 & 2 & 2 & 2 & 2 & With Probability $1 / 4$ \\
\hline State 3 & 2 & 2 & 2 & 2 & With Probability $1 / 4$ \\
\hline State 4 & 2 & 2 & 2 & 2 & With Probability $1 / 4$ \\
\hline
\end{tabular}

However, when country 1 and country 2 participate in group A and country 3 and country 4 in group $\mathrm{B}$, the following consumption is satisfied.

\footnotetext{
${ }^{6}$ Within this example, and for the purposes of simplicity, let us assume that there are Arrow-Debreu securities present in each mechanism. Also, representative agents have a common time preference and Constant Relative Risk Aversion (CRRA) utility
} 
Table A3. Consumption matrix

(in segmented markets)

\begin{tabular}{|l|c|c|c|c|c|}
\hline & Country 1 & Country 2 & Country 3 & Country 4 & \\
\hline State 1 & 3 & 3 & 1 & 1 & With Probability $1 / 4$ \\
\hline State 2 & 3 & 3 & 1 & 1 & With Probability $1 / 4$ \\
\hline State 3 & 1 & 1 & 3 & 3 & With Probability $1 / 4$ \\
\hline State 4 & 1 & 1 & 3 & 3 & With Probability $1 / 4$ \\
\hline
\end{tabular}

In this case, expected values and variances of consumption are identical between group A and group B. In particular, this implies that countries are indifferent between A and $\mathrm{B}$. The expectation value of consumption is identical in either case, but the variances vary according to each case. In this example, the endowment risks are diversifiable when all countries belong to the same mechanism. However, if the countries fall into two groups, then they cannot fully diversify the endowment risk. This is because even though there is no aggregate uncertainty, neither mechanism can offset the shocks. We attempt to introduce these circumstances into the familiar international representative agent economy.

\section{Appendix 2: Dynamic programming solution}

The time-invariant policy function and law of motion for capital stocks are derived as closed-form solutions using the guess-and-verify method. The first guess of the following policy function can be expressed as follows:

$$
c_{i t}=\phi_{i} \eta_{i t} k_{i t}
$$

where $\phi_{i}$ and $\eta_{i t}$ are undetermined coefficients. Substituting (A1) and (7) into (5), the following equation is satisfied:

$$
1=\beta \alpha E_{t}\left[\tilde{\theta}_{i t+1}\left(\frac{\phi_{i} \tilde{\eta}_{i t+1} k_{i t+1}}{\phi_{i} \eta_{i t} k_{i t}}\right)^{-\gamma}\right]
$$




$$
=\beta \alpha E_{t}\left[\tilde{\theta}_{i t+1}\left(\frac{\tilde{\eta}_{i t+1} k_{i t+1}}{\eta_{i t} k_{i t}}\right)^{-\gamma}\right]
$$

Then, the law of motion for capital stocks can be obtained as follows:

$$
k_{i t+1}=\left[\beta \alpha E_{t}\left(\tilde{\theta}_{i t+1} \tilde{\eta}_{i t+1}^{-\gamma}\right)\right]^{1 / \gamma} \eta_{i t} k_{i t}
$$

where $\eta$ is unknown parameter. Substituting (A4) into (8),

$$
C_{i t}=\theta_{i t} k_{i t}-k_{i t+1}=\left\{\theta_{i t}-\left[\beta \alpha E_{t}\left(\tilde{\theta}_{i t+1} \tilde{\eta}_{i t+1}^{-\gamma}\right)\right]^{1 / \gamma} \eta_{i t}\right\} k_{i t}
$$

Since equation (A5) must coincide with (A1), the undetermined coefficients $\phi_{i}$ and $\eta_{i t}$ can be derived:

$$
\begin{gathered}
\eta_{i t}=\theta_{i t} \\
\phi_{i}=1-\left[\beta \alpha E_{t}\left(\tilde{\theta}_{i t+1}^{-\gamma}\right)\right]^{1 / \gamma} \\
=1-\left[\beta \alpha E_{t}\left(\tilde{\theta}_{i t+1}^{-\gamma}\right)\right]^{1 / \gamma}
\end{gathered}
$$

It is possible to obtain the policy function (9) and law of motion for capital stock (10) by substituting the coefficients (A6) and (A7) into (A1) and (A4).

\section{Appendix 3: Growth}

The calculus of the relation $\partial \psi_{i} / \partial \mu$ can be performed with respect to A as follows, and it can be extended for B without loss of generality:

$$
\begin{aligned}
\frac{\partial \psi_{A}}{\partial \mu}=\frac{1-\gamma}{2 \gamma} & \lambda \underbrace{\lambda(\beta \alpha)^{\frac{1+\gamma}{\gamma}}}_{+}\{\underbrace{[\bar{\theta}-\lambda(1-\mu)]^{-\gamma}-[\bar{\theta}+\lambda(1-\mu)]^{-\gamma}}_{+}\} \\
\times & \underbrace{\left\{[\bar{\theta}-\lambda(1-\mu)]^{1-\gamma}+[\bar{\theta}+\lambda(1-\mu)]^{1-\gamma}\right\}^{\frac{1+\gamma}{\gamma}}}_{+}
\end{aligned}
$$

The sign of the above equation is dependent on $1-\gamma$. Note that $\mu$ represents the 
participation rate in group A. Therefore, a higher degree of participation in group A induces an increase in growth within $\mathrm{A}$ if $0<\gamma<1$ and a decrease if $1<\gamma$.

\section{Appendix 4: The proof of Proposition 2 and Proposition 3}

First, the following lemma is introduced:

Lemma 1 Welfare monotonicity

If $\gamma \alpha>(\gamma+\alpha-1) \psi_{i}$ is satisfied, then $V_{A}$ is increasing and $V_{B}$ is decreasing in $\mu$. Similarly, when $\gamma \alpha<(\gamma+\alpha-1) \psi_{i}$, then $V_{A}$ is decreasing and $V_{B}$ is increasing in $\mu$.

The differentiation of $V_{i}$ with respect to $\mu$ is as follows:

$$
\frac{\partial V_{i}}{\partial \mu}=\frac{\lambda \Gamma_{i}(\mu)\left\{1-\left[\beta \alpha \Lambda_{i}(\mu)\right]\right\}^{-\gamma}\left\{1+\frac{1-\gamma-\alpha}{\gamma \alpha}\left[\beta \alpha \Lambda_{i}(\mu)\right]^{\frac{1}{\gamma}}\right\} k_{0}^{1-\gamma}}{\left\{1-\beta\left[\beta \alpha \Lambda_{i}(\mu)\right]^{\frac{1-\gamma}{-\gamma}} \Lambda_{i}(\mu)\right\}^{2}}
$$

where

$$
\begin{gathered}
\Lambda_{A}(\mu)=0.5[\bar{\theta}+\lambda(1-\mu)]^{1-\gamma}+0.5[\bar{\theta}-\lambda(1-\mu)]^{1-\gamma}(>0) \\
\Lambda_{B}(\mu)=0.5[\bar{\theta}+\lambda \mu]^{1-\gamma}+0.5[\bar{\theta}-\lambda \mu]^{1-\gamma}(>0) \\
\Gamma_{A}(\mu)=-0.5[\bar{\theta}+\lambda(1-\mu)]^{1-\gamma}+0.5[\bar{\theta}-\lambda(1-\mu)]^{1-\gamma}(>0) \\
\Gamma_{B}(\mu)=0.5[\bar{\theta}+\lambda \mu]^{-\gamma}-0.5[\bar{\theta}-\lambda \mu]^{-\gamma}(<0)
\end{gathered}
$$

This implies that the shape of the value function depends on both the degree of risk aversion and expected marginal product of capital stock.

\section{Multiple equilibria:}

If $(\gamma+\alpha-1) \psi_{i}<\gamma \alpha, V_{A}(0)<V_{B}(0)$, and $V_{B}(1)<V_{A}(1)$, the intermediate value theorem applies, and there exists a fixed intermediate point $\mu^{*}=0.5$ since $V_{A}$ and $V_{B}$ are symmetric functions about $\mu$. When the beliefs about the degree of market integration are such that $\mu=0$, the equilibrium comes from the incentive for countries to participate in B because 
its value function dominates that of A. Also, the equilibrium where $\mu=1$ reflects the incentive for countries to instead participate in $\mathrm{A}$, whose value function dominates that of B.

\section{Unique equilibrium:}

As with multiple equilibria, if $\gamma \alpha<(\gamma+\alpha-1) \psi_{i}, V_{B}(0)<V_{A}(0)$, and $V_{A}(1)<V_{B}(1)$, are satisfied, then it is possible to apply the intermediate value theorem, which implies the existence of a fixed intermediate point $\mu^{*}=0.5$. However, full market integration is not conducive to equilibrium because in either case, the value function of one group is dominated by the other. 